\title{
Incubation Programs from Public Research Organizations as Catalysts for Open Business Ecosystems
}

\author{
Sven H. De Cleyn, Frank Gielen, and Jan Coppens
}

\author{
"In many cases, the more you try to compete," \\ the less competitive you actually are. \\ Kathy Sierra \\ Co-creator of the Head First book series
}

\begin{abstract}
In many economies, new knowledge and technology creation and transfer towards local entities and new startups have been recognized as catalysts for industry renewal and tools for safeguarding (or even enhancing) a region's employment and prosperity. This article presents a case study of iMinds, a network organization in Flanders, Belgium. The organization fosters interdisciplinary research in information and communication technologies (ICT) and strongly engages in transferring these new technologies towards local actors and in creating and supporting new startups. iMinds' incubation and entrepreneurship programs act as catalysts for open innovation and company startup activities in the Flemish region.
\end{abstract}

\section{Introduction}

Traditionally, Flanders - and by extension Belgium has been viewed as an interesting location for entering the Western European market. In the 1960s, many large European and American multinationals established production sites and sales and distribution organizations in the region, which brought jobs and welfare. Some of these multinationals were electronics manufacturing companies, such as Alcatel, Siemens and Philips, which increasingly engaged in information and communication technology (ICT) activities. To support these large ICT companies, a large number of suppliers and service providers became established in the region.

The growing group of small and medium-sized enterprises (SMEs) further increased in importance after the divestiture and relocation of corporate activities of the multinational players during the 1990s and early-2000s (similar to what happened in other regions around the world, such as Canada's Capital Region: see Bailetti and Bot [2013; timreview.ca/article/658] for details). Increasingly, employment, growth, and the preservation of prosperity has been depending on these SMEs, which operate in a small, open economy. The latter characteristic forces them to become born-global ventures, competing on a local and international level.

This changing environment called for action and policy change, which could no longer aim to attract activities from large multinational players. As a reaction to these changes, the Flemish government developed new strategic initiatives for certain domains: in 1984, the Interuniversity Microelectronics Centre (Imec; tinyurl.com/ d25ku98) was established to foster ground-breaking research activities in micro-electronics; in 1991, the government founded the Flemish Institute for Technological Research (VITO; tinyurl.com/d9n2wfp) to perform research on cleantech and environmental technologies; and then in 1996, the Flemish Institute for Biotechnology (VIB; tinyurl.com/crbtfru) was founded. 


\title{
Incubation Programs as Catalysts for Open Business Ecosystems
}

\author{
Sven H. De Cleyn, Frank Gielen, and Jan Coppens
}

The latest government initiative of this type was founded in 2004 as an independent research institute: iMinds (iminds.be), formerly known as the Interdisciplinary Institute for Broadband Technology. iMinds was given the task of developing demand-driven solutions (i.e., research, innovation and entrepreneurial ventures) for the ICT sector and fostering the business and societal application and adoption of newly developed technologies, knowledge, products, and services. Creating and maintaining a steady supply of new knowledge and technologies in this fast-moving industry has been recognized as crucial for a healthy ICT sector. Thus, the need for innovation and commercialization has been a driving force behind iMinds' activities since its inception. This strategy is supported by findings from academic research, such as a study that pointed out that Europe has fewer "young innovative companies" compared to the United States, while this startup group shows the largest potential in terms of contribution to new economic activities in a region (Veugelers, 2009; tinyurl.com/d55p62f). A clear pillar of activities fostering commercialization and the creation of new technologybased ventures could thus contribute to the business dynamics in a region.

This article describes the iMinds entrepreneurship incubation program as a case study to show how a public research organization can act as a catalyst for open innovation and company startup activities. First, we provide details of the iMinds incubation program. Second, we describe the development and evolution of iMinds' networking function and its emphasis on open collaboration. Finally, we provide conclusions.

\section{The iMinds Incubation Program}

iMinds was set up as a focal-point organization designed to link university research to the needs of business and to help build a positive startup and venturing climate. As such, it was designed to be the catalyst for a cluster of innovation (Engel and del Palacio, 2009; tinyurl .com/c3mrauv), a model that had been applied 10 years earlier in the area of biotechnology with the creation of the Flemish Institute of Biotechnology (VIB), which had a similar mission. Over the 20-year period since the VIB was founded, we have witnessed the emergence of a strong biotechnology cluster around this initiative, and the purpose of iMinds is to achieve the same success in ICT. Furthermore, organizations like iMinds form an important part of the "triple helix" model, which creates constructive and mutually reinforcing activities between academia, government, and industry (Etzkowitz, 1998: tinyurl.com/btehl65; Leydesdorff, 2000: tinyurl.com/cy84fo7).
The approach that iMinds adopts in transferring knowledge and technologies towards partners and newly created technology-based ventures (spin-offs and startups) is somewhat different from traditional approaches. Although most universities and public research organizations focus solely on monetizing their own intellectual-property assets, iMinds acts as network integrator by fostering interaction and open collaboration (sometimes, but not always, in an open-innovation context) between various actors in the ecosystem. Even though the collaborative and demand-driven research projects form an important part of these activities (roughly 25 out of the 40 million EUR of iMinds' annual budget are spent on collaborative and demand-driven research), they fall outside of the scope of this article. The incubation and entrepreneurship activities target the support of all ICT-driven entrepreneurial and intrapreneurial projects, whether emerging from iMinds research (or iMinds' five Flemish partner universities) or from external entrepreneurs.

In this regard, several tools are used to foster the open support and interactions between various stakeholders:

1. iMinds' incubation program aims at supporting academic entrepreneurs, students, and independent entrepreneurs, especially in the pre-seed and seed phases. The program is supported by specific tools and projects that target different aspects of the entrepreneurial journey: opportunity recognition workshops to identify ideas that can become business opportunities; entrepreneurial bootcamps that focus on business modeling and (seed) investor readiness and the iStart incubation projects that enable the creation of early-stage businesses by providing financial support (pre-seed funding); coaching and mentoring; an entrepreneur-in-residence program; access to iMinds' network and to specialists for professional advice on, for example, financial issues, branding and sales, legal matters, and intellectual property.

2. As a network integrator, iMinds has set up a "virtual incubator" program to create spillover effects to local and regional communities of entrepreneurs and creative people. Through this program, cooperation with locally embedded (physical) incubators and coworking spaces is initiated. In these incubators, iMinds supports networking events and acts as catalyst to bridge the gap between local communities and actors in other regions. Entrepreneurs supported by the incubation program are also encouraged to establish themselves in one of these virtual incubator facilities to increase their embeddedness in local 


\title{
Incubation Programs as Catalysts for Open Business Ecosystems
}

\author{
Sven H. De Cleyn, Frank Gielen, and Jan Coppens
}

communities of entrepreneurs and creative people. This link increases spillover effects and interactions with other kindred spirits, leading to mutual learning, cooperation, and ultimately, joint business (i.e., coopetition instead of competition).

3. Through the student entrepreneurship program, we support the universities and university colleges in their efforts to embed entrepreneurship and entrepreneurial behaviour as professional skill development in their curricula. Our economic system is evolving from a corporate-managed model to a networked-entrepreneurial model and the education system needs prepare students for this new environment. Some students will want to become entrepreneurs but all of them will need to entrepreneurial if they want to be top performers in their professional career. The iMinds incubator plays a key role in this education process as it provides a real-world environment in which students can learn entrepreneurship "by doing" and where universities and industry work together in an educational context creating a win-win situation. Universities differentiate themselves with innovative education programs and future employers hire graduates that are better prepared for their future jobs. The student entrepreneurship program includes series of workshops, bootcamps, and networking events to give students initial coaching and networking opportunities to develop entrepreneurial skills and an appetite for entrepreneurship.

4. Opening up the program does not only refer to the Flemish or Belgian context. Through an internationalization program, iMinds stimulates startups, spinoffs, and SMEs in its network to act on an international level and connect to other clusters of innovation worldwide (e.g., East and West coasts of the United States, Singapore as hub for South-East Asia, and other European "hotspots"). In this sense, the internationalization tools, including (local) coaching and travel and housing support, helps connect iMinds and its ventures to global clusters of innovation (Engel and del Palacio, 2011; tinyurl.com/c26ffps). This approach also helps startups to be aware of the opportunities and necessity to become global players, which in turn favours job creation. According to Bailetti and Bot (2013; timreview.ca/article/658), this emphasis on early globalization should be one of the main pillars of government-funded programs.
These iMinds programs, which form only a part of the total iMinds incubation and entrepreneurship toolbox, are open to any entrepreneur with an ICT-related or enabled project that is willing to start their business in the Flemish or Brussels capital region. This approach clearly enables iMinds to foster the creation of a real ICT ecosystem, in which all relevant stakeholders (including universities, large corporations, SMEs, startups, entrepreneurs, students, government organizations, other entrepreneurship-supporting organizations, and non-profit organizations) interact frequently, and spillover effects are generated. The next section will illustrate that the individual programs are relevant as such, but the integrated approach of the incubation and entrepreneurship program at local and regional levels is the real differentiator.

\section{Building a Network and Fostering Open Cooperation}

The approach adopted by most technology transfer offices of universities and other public research organizations is to support the commercialization and societal impact of the knowledge and technologies developed in their institutions. The same approach was originally the focus of iMinds' incubation and entrepreneurship programs. However, as Figure 1 illustrates, the impact remained rather limited in terms of the number of newly created spin-off projects, at least prior to 2011 when the incubation program was started.

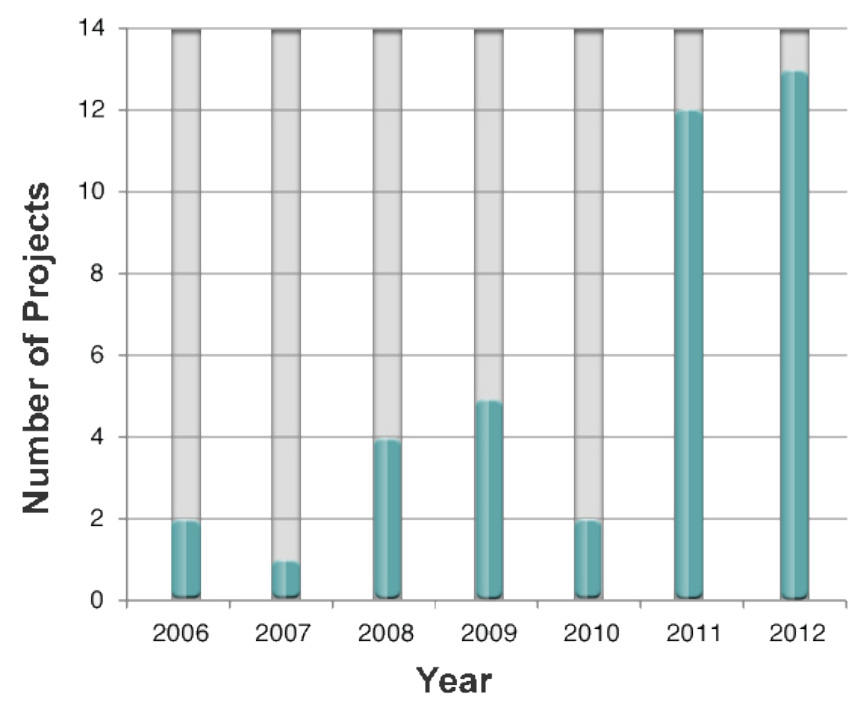

Figure 1. Number of new iMinds spin-off projects per year 


\section{Incubation Programs as Catalysts for Open Business Ecosystems}

\section{Sven H. De Cleyn, Frank Gielen, and Jan Coppens}

The shift towards a networking function for the incubation and entrepreneurship programs, which already existed at a research level through collaborative and demand-driven research projects, strengthened these programs and created an important amount of spillover effects towards other actors and reinforced the open-cooperation mode with various stakeholders, as described initially by the triple helix model of university-industry-government relations. Some shortterm effects are already visible, and some mid- to longterm effects are expected to arise:

1. Researchers and entrepreneurs are engaging to a larger extent in local communities through the networking events, workshops, bootcamps, and other activities. This effect is further reinforced through the virtual incubator network.

2. Increasingly, entrepreneurs external to iMinds are starting to find their ways to our programs and engage in the iMinds community at different levels. Figure 2 illustrates this process and early data about the number of projects supported. Since opening up the incubation program in the summer of 2011, the number of entrepreneurs coming to iMinds for support has been rising. This amount pales before the number of startups currently supported by large programs such as Y Combinator (ycombinator.com), which has supported over 500 startups since 2005 and added 82 new startups in the summer of 2012 alone
(Graham, 2012; tinyurl.com/37uzojs). However, keeping in mind the fact that Y Combinator supported only 8 startups during its first cycle in summer 2005 and the young age of the incubation program at iMinds, the early results shown in Figure 2 are encouraging.

What is even more important, is that the entrepreneurs that originally had been independent of iMinds research started engaging more frequently in collaborative efforts with iMinds' researchers. This growing amount of open cooperation increases direct and indirect spillover effects between iMinds research and other stakeholders - in both directions. Furthermore, it creates more options towards job flexibility between academia and industry, again in both directions. The model's success is further proven by the amount of additional equity funding the incubation projects managed to close after being engaged in the iMinds incubation program; for example, incubation projects benefitted from a $4.7 x$ funding multiplier in 2012, as shown in Figure 2.

3. Even though opening up these programs required an initial investment in terms of people and putting programs in place, the returns for the research organization are manifold: i) human and social capital development for researchers, students, and entrepreneurs have grown through the interactions with various stakeholders and the increasing mobility of people between different actor categories; ii) a grow-

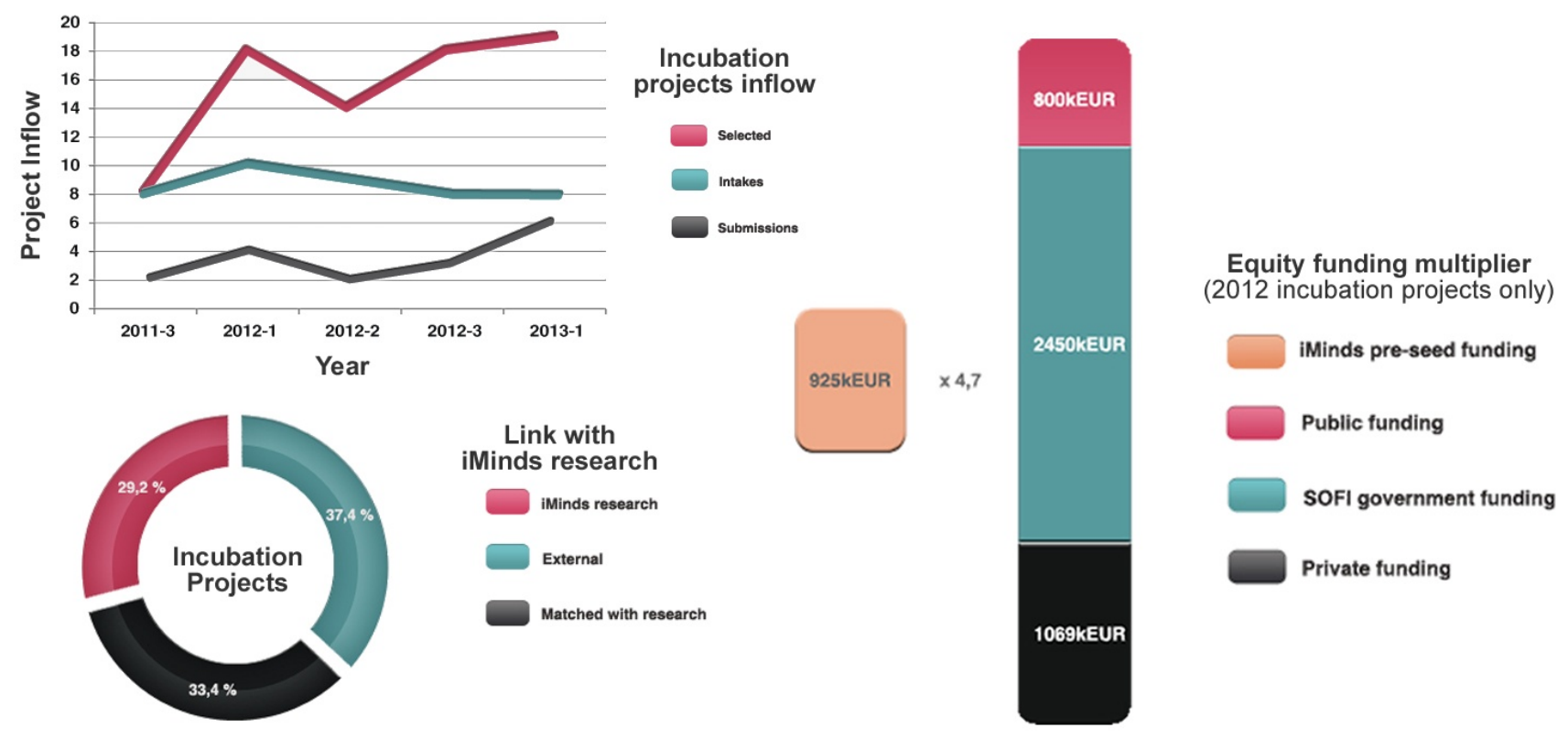

Figure 2. Startup engagement with the iMinds incubation program in terms of project inflow, links with research, and sources of funding 


\title{
Incubation Programs as Catalysts for Open Business Ecosystems
}

\author{
Sven H. De Cleyn, Frank Gielen, and Jan Coppens
}

ing network of people and organizations with new ideas and insights has emerged, to further push the boundaries of knowledge and technologies; and iii) financial return for the research organization will most likely appear, directly through license agreements and equity participation and indirectly through additional research projects together with the research organization (the latter is expected to bring the greatest financial return).

4. An entire ecosystem of entrepreneurs, researchers, service providers, and local entities is developing, allowing participants to cooperate with - and support the success of - new commercialization initiatives.

5. Within the ecosystem, startups are increasingly cooperating with each other and with other small and large companies . Furthermore, the first, albeit small joint business propositions are starting to arise. In this regard, these startups are expected to start reinforcing each other and developing joint offers instead of competing with each other.

The effect of the open-cooperation mode is not limited to the direct programs through which iMinds support incubation and entrepreneurship activities. An entire ecosystem of experts and partners becomes apparent, and a partner portfolio of now over 900 organizations has developed. Furthermore, links with various business angels, venture capitalists, and other financers have been set up. Policy initiatives have started to develop around these core activities, and a network of professional service providers - to support spin-offs and startups with advice and support for legal matters, intellectual property, branding, and other matters - has emerged in a natural way. These connections illustrate the indirect effects of opening up incubation programs to engage a wider community of people in incubation and entrepreneurship activities around the core research activities.
Recently in this journal, Bailetti and Bot (2013; timreview.ca/article/658) described a similar program Lead To Win (leadtowin.ca) - that integrates the efforts of various stakeholders in supporting technology entrepreneurship in Canada's Capital Region, and they identified job creation as one of the most important functions of an incubation program. We share this view and highlight the importance of the 100 jobs that the iMinds incubation program has created in the Flanders region. By connecting various actors and stakeholders that supporting entrepreneurs and technology-based ventures, the iMinds incubation program plays a direct role in supporting entrepreneurship and job creation.

\section{Conclusion}

The traditional approach to technology transfer and entrepreneurship activities at universities and public research organizations emphasizes the commercial or societal applications of knowledge and technologies developed within a given research organization. This article has discussed the case study of iMinds, a public ICT research organization in Flanders, Belgium, where the incubation and entrepreneurship activities have been opened up towards the broader ICT community in the region.

The way iMinds supports present and future entrepreneurs strongly differs from this traditional model. The new model of open cooperation with all relevant stakeholders and embracing external ideas, as well as external entrepreneurs, creates an entire ecosystem of actors amongst which spillover effects are generated. The first direct and indirect benefits for all entities start to appear, in terms of more intensive cooperation and interaction, human and social capital development, spillover effects, and mutual reinforcement. The fuel powering the creation of this ecosystem is the set of tools in the iMinds incubation and entrepreneurship program. 


\title{
Incubation Programs as Catalysts for Open Business Ecosystems
}

Sven H. De Cleyn, Frank Gielen, and Jan Coppens

\begin{abstract}
About the Authors
Sven H. De Cleyn is Incubation Programs Manager at iMinds, a strategic ICT research centre founded by the Flemish government, where he supports new startup and spin-off projects from their pre-seed phase onwards. He received a $\mathrm{PhD}$ in Applied Economics at Antwerp University, Belgium, for his research on the early development of academic spin-offs in Europe. He currently also lectures on entrepreneurship at Karel de Grote University College in Antwerp, he coaches students at the Antwerp Management School, and he conducts research on high-tech entrepreneurship and academic spin-offs as a post-doc researcher at the University of Antwerp.
\end{abstract}

Frank Gielen is Director of Incubation \& Entrepreneurship at iMinds. He holds a PhD in Computer Science from the Free University of Brussels, Belgium. $\mathrm{He}$ is also Professor at Ghent University, Belgium, where he teaches courses on software and technology entrepreneurship and drives student entrepreneurship through the "Durf Ondernemen" program. He has entrepreneurial experience through different roles in several ventures.

Jan Coppens obtained his $\mathrm{PhD}$ in computer science engineering from the Information Technology Department of Ghent University, Belgium, in 2006. He continued his research in network technology at Alcatel-Lucent Bell Labs, where he managed several research projects. As part of an internal corporate venture effort, Jan founded and led a small team of entrepreneurs to bring innovative home-networking technology under $\mathrm{CxO}$ attention and push it along the product roadmap. At the end of 2007, he left Bell Labs to join the Business Technology Office of McKinsey \& Company. Currently, Jan is responsible for marketing and business development at the iMinds Incubation \& Entrepreneurship program.

Citation: De Cleyn, S.H., F. Gielen, and J. Coppens. 2013.

Incubation Programs from Public Research Organizations

(cc) BY

as Catalysts for Open Business Ecosystems. Technology

Innovation Management Review. April 2013: X-Y.

Keywords: technology entrepreneurship, incubation programs, startup ecosystem, clusters of innovation, university-industry interaction 